\title{
Meta-Analysis of Heavy Metal Partitioning and Allocation Plasticity of Nicotiana glauca Graham (Solanaceae)
}

\author{
Salama Mohamed El-Darier, Ream Ibrahim Marzouk*, Shimaa Abdel Razek Rashed \\ Botany and Microbiology Department, Faculty of Science, Alexandria University, P.O. Box 21511.Alexandria. Egypt. \\ Correspondence Author: Ream Ibrahim Marzouk, Botany and Microbiology Department, Faculty of Science, Alexandria University, P.O. Box \\ 21511.Alexandria. Egypt. e-mail: reammarzouk@yahoo.com. \\ Tel: +2065527760
}

Received date: 11 January, Accepted date: 10 March 2019, Online date: 20 March 2019

Copyright: (C) 2019 Salama Mohamed El-Darier et al., This is an open-access article distributed under the terms of the Creative Commons Attribution License, which permits unrestricted use, distribution, and reproduction in any medium, provided the original author and source are credited.

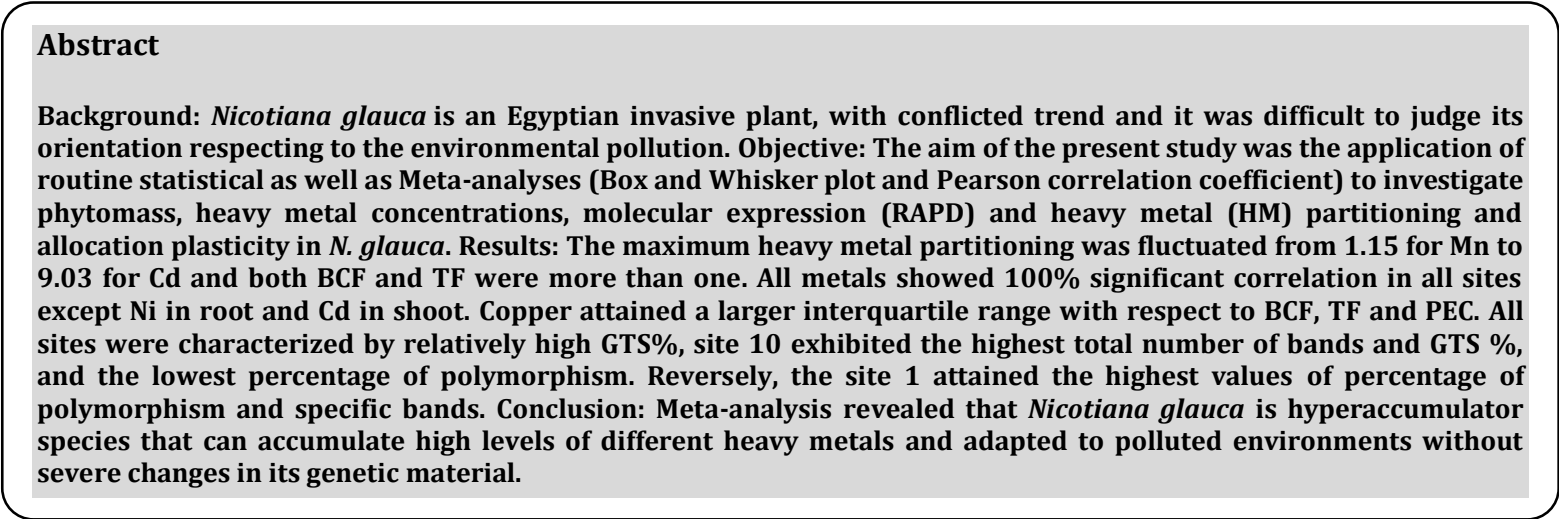

Key words: Heavy metals, Hyperaccumulator, Genomic template stability, Meta-analysis, Nicotiana glauca, Phytomass, RAPD.

\section{INTRODUCTION}

Meta-analysis is applied statistical methods to combine results across a set of populations, the units of analysis are the individual observations, or data from independent experiments to determine the impact of various variables on both phenotypic and genotypic alterations [1, 2]. The science of ecology can only advance if we are able to discern the exception from the rule, generalize that synthesizes current knowledge and guide new basic research and practical applications [3]. Heavy metal partitioning and their allocation potentiality in plants are of growing concern [4]. Genotoxicity by heavy metals in polluted ecosystems induced several cellular stress responses that led to the damage of different cellular components such as membranes, proteins and DNA [5, 6]. Phenotypic plasticity and adaptation were two mechanisms provided protection against cell damage and maintenance of photosynthetic function, which played a key role for plant survival and growth [7, 8]. Nicotiana glauca is an Egyptian invasive plant, drought tolerant and grows rapidly forming dense stands. There was a high risk of introduction to new regions because it displayed a number of ecological traits leading to invasiveness $[9,10]$. The trend of this plant was conflicted; it has inhibitory and or stimulatory effects on growth of some crop and vegetable species and it was difficult to judge its orientation. Therefore, the main objective was to evaluate — via Meta-analysis — plant phytomass, heavy metal (HM) partitioning and assessment of both bio-concentration and translocation factors, phytoextraction coefficient and allocation plasticity as well as molecular expression in N. glauca.

\subsection{Collection of specimens:}

\section{MATERIAL AND METHODS}

Forty-two individuals of $N$. glauca were excavated in 2015-2016 from fourteen natural sites, three from each population, at Burg El-Arab and Amreyya districts. Samples were selected in order to cover the most dominant polluted habitats within the range of the species distribution. Voucher specimens were deposited at the Alexandria University herbarium, Egypt (ALEX).

\subsection{Determination of phytomass}

Advances in Environmental Biology

ISSN-1995-0756 EISSN-1998-1066 
Samples of plant materials were dried in oven at $70^{\circ} \mathrm{C}$ till constant weight to determine the total phytomass (g/individual) and the sharing percentage of each organ were calculated [11]. Indices of phytomass partitioning were used to assess their allocation in roots relative to shoots.

Phytomass partitioning $=\mathrm{P}_{\text {root }} / \mathrm{P}_{\text {shoot }}$ (Where, $\mathrm{P}_{\text {root }}$ is the phytomass of root and $\mathrm{P}_{\text {shoot }}$ is the phytomass of shoot).

Sharing percentage $=\mathrm{W}_{\text {organ }} / \mathrm{T}_{\text {Phytomass }} \mathrm{X} 100$ (Where, $\mathrm{W}_{\text {organ }}$ is the weight of the organ and $\mathrm{T}_{\text {Phytomass }}$ is the total Phytomass of the individual).

\subsection{Determination of heavy metal (HM) concentrations}

The concentrations (ppm) of some HMs (Pb, $\mathrm{Zn}, \mathrm{Fe}, \mathrm{Cd}, \mathrm{Mn}, \mathrm{Co}, \mathrm{Cu}$, and $\mathrm{Ni}$ ) were estimated by using atomic absorption spectrophotometer [12].

$\mathrm{HM}$ partitioning $=\mathrm{C}_{\text {root }} / \mathrm{C}_{\text {shoot }}$ (Where, $\mathrm{C}_{\text {root }}$ is the concentration of metal in root and $\mathrm{C}_{\text {shoot }}$ is the concentration of metal in shoot) [11].

\subsection{Heavy metal equation}

Bio-concentration factor $(\mathrm{BCF})=\mathrm{C}_{\text {root }} / \mathrm{C}_{\text {soil }}$ (Where, $\mathrm{C}_{\text {root }}$ is the concentration of metal in root and $\mathrm{C}_{\text {soil }}$ is the concentration of metal in soil) [13].

Translocation factor $(\mathrm{TF})=\mathrm{C}_{\text {shoot }} / \mathrm{C}_{\text {root }}$ (Where, $\mathrm{C}_{\text {shoot }}$ is the concentration of metal in shoot and $\mathrm{C}_{\text {root }}$ is the concentration of metal in root) [13].

The phytoextraction coefficient $(\mathrm{PEC})=\mathrm{C}_{\text {shoot }} / \mathrm{C}_{\text {soil }}$ (Where, $\mathrm{C}_{\text {shoot }}$ is the concentration of metal in shoot and $\mathrm{C}$ soil is the concentration of metal in soil) [14].

\subsection{Random amplified polymorphic DNA (RAPD)}

The DNA was extracted from one-gram fresh leaves through Gene jet genomic DNA extraction kit, fermentase life science, according to manufacturer protocol of Omega Co. (USA. LMt.). Total genomic DNA was amplified through Gene Amp Polymerase Chain Reaction (PCR) system cycle by using five random primers; RAPD- 1 (GGTGCGGGAA), RAPD- 2 (GTTTCGCTCC), RAPD- 3 (GTAGACCCGT), RAPD- 4 (AAGAGCCCGT) and RAPD- 5 (AACGCGCAAC). The reaction consisted of 40 cycles; each cycle with denaturation at $94^{\circ} \mathrm{C}$ for $1 \mathrm{~min}$. followed by annealing at $55^{\circ} \mathrm{C}$ for $1 \mathrm{sec}$. and extension at $72^{\circ} \mathrm{C}$ for $2 \mathrm{~min}$. There was an initial delay for $15 \mathrm{~min}$. at $95^{\circ} \mathrm{C}$ at the beginning of the first cycle and $10 \mathrm{~min}$. delay at $72^{\circ} \mathrm{C}$ at the end of the last cycle as a post extension step [15]. The amplification products and Standard DNA (mixture of $\chi$ Hind III and $\phi X$ 179 DNA /Hae III) were analysed by electrophoresis in a $1.5 \%$ agarose, supplemented with ethidium bromide $\left(0.5 \mu \mathrm{g} \mathrm{ml}{ }^{-1}\right)$. The gels were examined on UV transilluminator and photographed by using Polaroid film type Photo Doc-It ${ }^{\mathrm{TM}}$ Imaging. Sharp discrete bands counted and the total number of bands produced per each primer, the percentage of polymorphic bands, and the number of specific bands. The percentage of polymorphic band per primer was calculated; (polymorphic bands / Total bands per primer) X 100. Genomic template stability (GTS \%) was determined; (1-a/n) X100 — a (appearance of new bands and disappearance normal bands), and n (total number of bands) [16].

\subsection{Routine statistical analyses}

The appropriate data were subjected to standard one-way analysis of variance (ANOVA) using COSTAT 2.00 statistical analysis software manufactured by Cohort software company [17]. The significant difference was detected by ANOVA test, while the significance between sites was done using Post Hoc Test (Tukey).

\subsection{Meta-analysis employment}

The Box and Whiskers plot for BCF, TF and PEC have been calculated as a response ratio to be used as a metric of the effect size - the standard correlation coefficient $(\mathrm{r})$ - in Meta-analysis. This ratio has been calculated as $\log \mathrm{BCF}=\log \left(\mathrm{C}_{\mathrm{root}} / \mathrm{C}\right.$ soil $), \log \mathrm{TF}$ $=\log \left(\mathrm{C}_{\text {shoot }} / \mathrm{C}_{\text {root }}\right)$ and $\log \mathrm{PEC}=\log \left(\mathrm{C}_{\text {shoot }} / \mathrm{C}_{\text {root }}\right)$ where $\mathrm{C}_{\text {root }}, \mathrm{C}_{\text {shoot }}$ and $\mathrm{C}_{\text {soil }}$ were the mean values for heavy metal concentration in root and shoot. A box and whiskers plot displayed the five-number summary of a set of data, these numbers are the $\mathrm{Q}_{0}$ (Minimum), $\mathrm{Q}_{1}$ (Quartile 1), $\mathrm{Q}_{2}$ (Median), $\mathrm{Q}_{3}$ (quartile 3) and $\mathrm{Q}_{4}$ (Maximum), then the information from the five-number summary was represented using box and whiskers plot [18].

Pearson correlation coefficient was used in Comprehensive Meta-analysis (CMA) software (Version 2.2.027) which applied to determine the relationships between allocation plasticity and HM partitioning among $N$. glauca populations [19, 20, 21].

\subsection{Phytomass}

\section{RESULTS}

The average phytomass of stem showed the highest values, while flowers achieved the lowest ones. The total phytomass ranged from 2553.91 to 478.39 g/individual in Sites 5 and 1, respectively. Consequently, the sharing percentage of stem and flowers exhibited the highest and lowest percentage, respectively. The values of phytomass partitioning in all sites were less than 1 (Table $1)$.

\subsection{Heavy metals}


The variation in HM concentrations ( $\mathrm{ppm})$ in root and shoot was significant $(\mathrm{p}<0.001)$. Iron achieved the highest values, while Cd showed the lowest compared to the other investigated heavy metals (Figure 1). The maximum heavy metal partitioning was fluctuated from 1.15 for Mn to 9.03 for Cd (Figure 2).

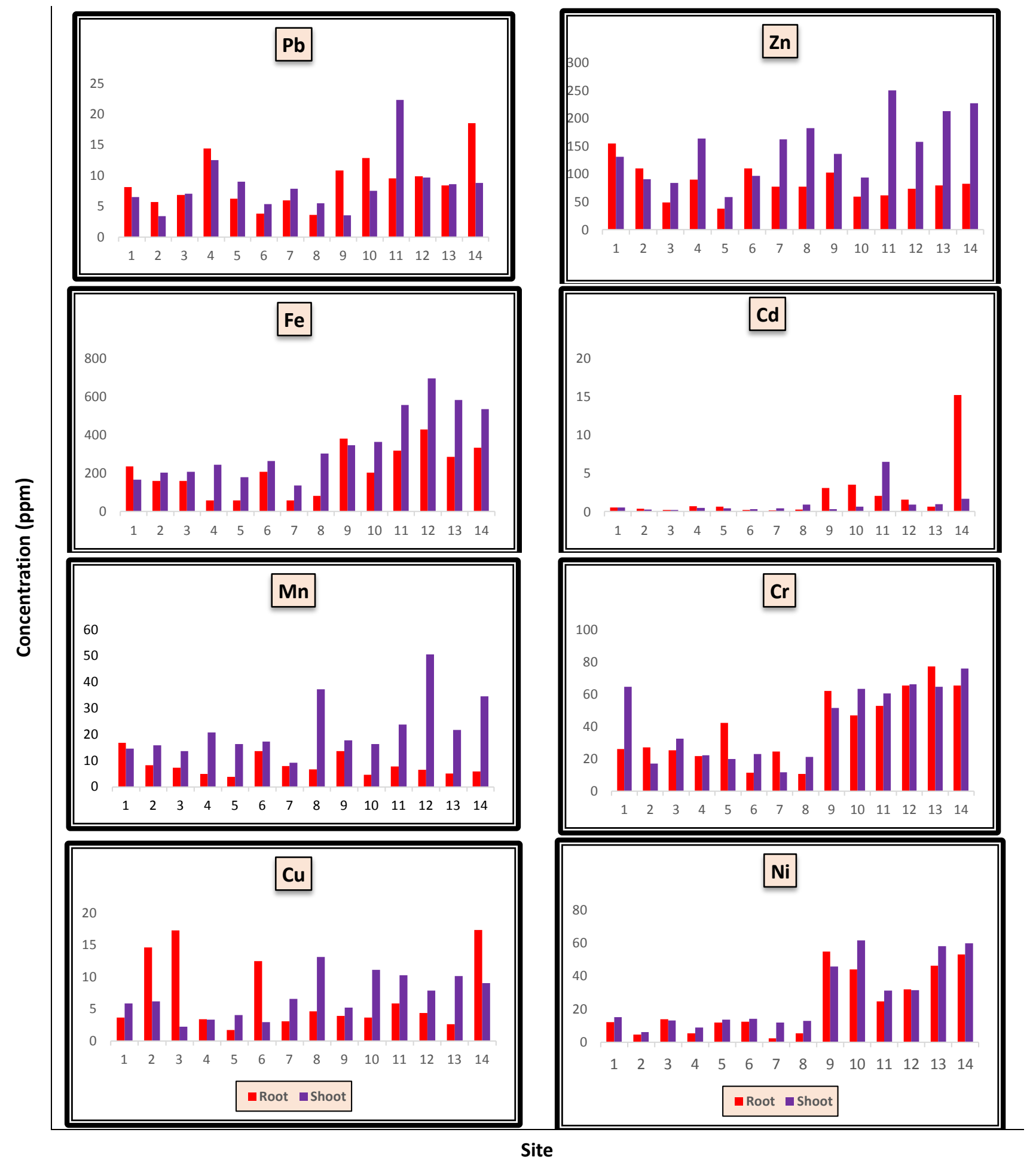

Fig. 1: Variation in concentration ( $\mathrm{ppm})$ of some heavy metals in root and shoot of Nicotiana glauca growing in 14 different sites at Burg El-Arab and Amreyya districts. 
4

Citation : Salama Mohamed El-Darier et al., 2019. Meta-Analysis of Heavy Metal Partitioning and Allocation Plasticity of Nicotiana glauca Graham (Solanaceae) Advances in Environmental Biology 13(3): 1-13. DOI: 10.22587/aeb.2019.13.3.1

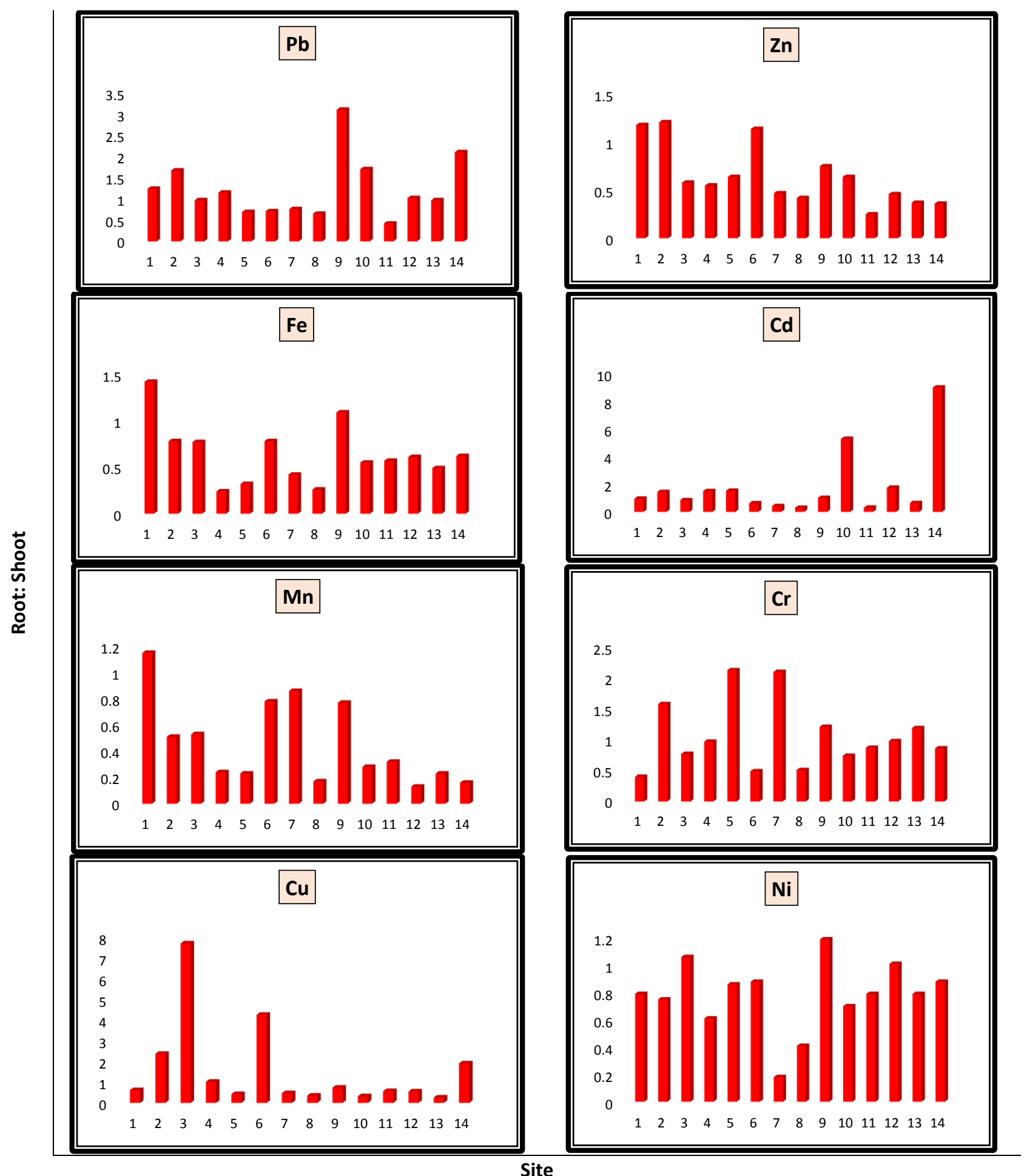

Fig. 2: Partitioning (root: shoot) of some heavy metals in Nicotiana glauca growing in 14 different sites at Burg El-Arab and Amreyya districts. 


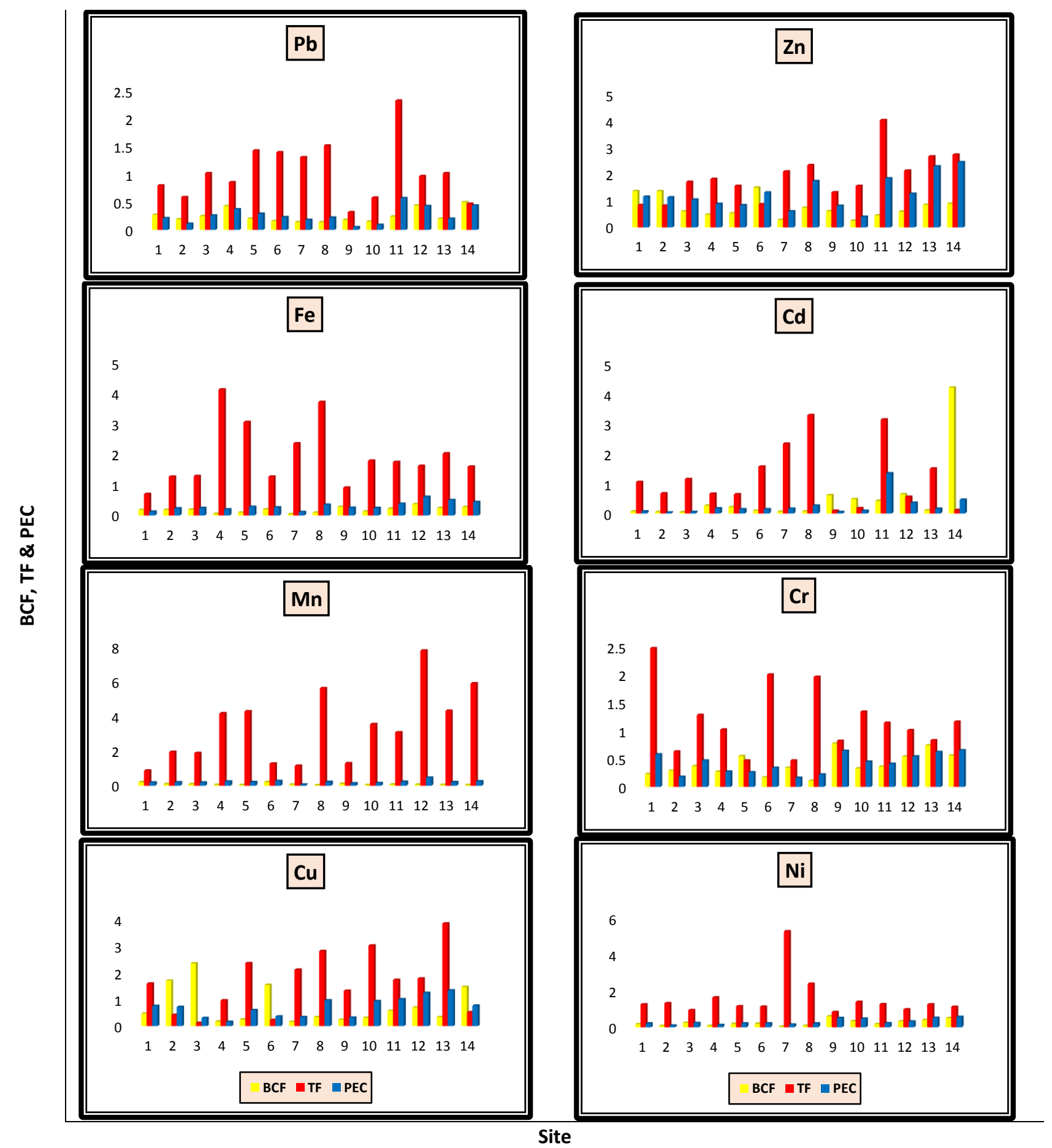

Fig. 3: Variation in bioconcentration and translocation factors as well as phytoextraction coefficient of some heavy metals of Nicotiana glauca growing in 14 different sites at Burg El-Arab and Amreyya districts. 


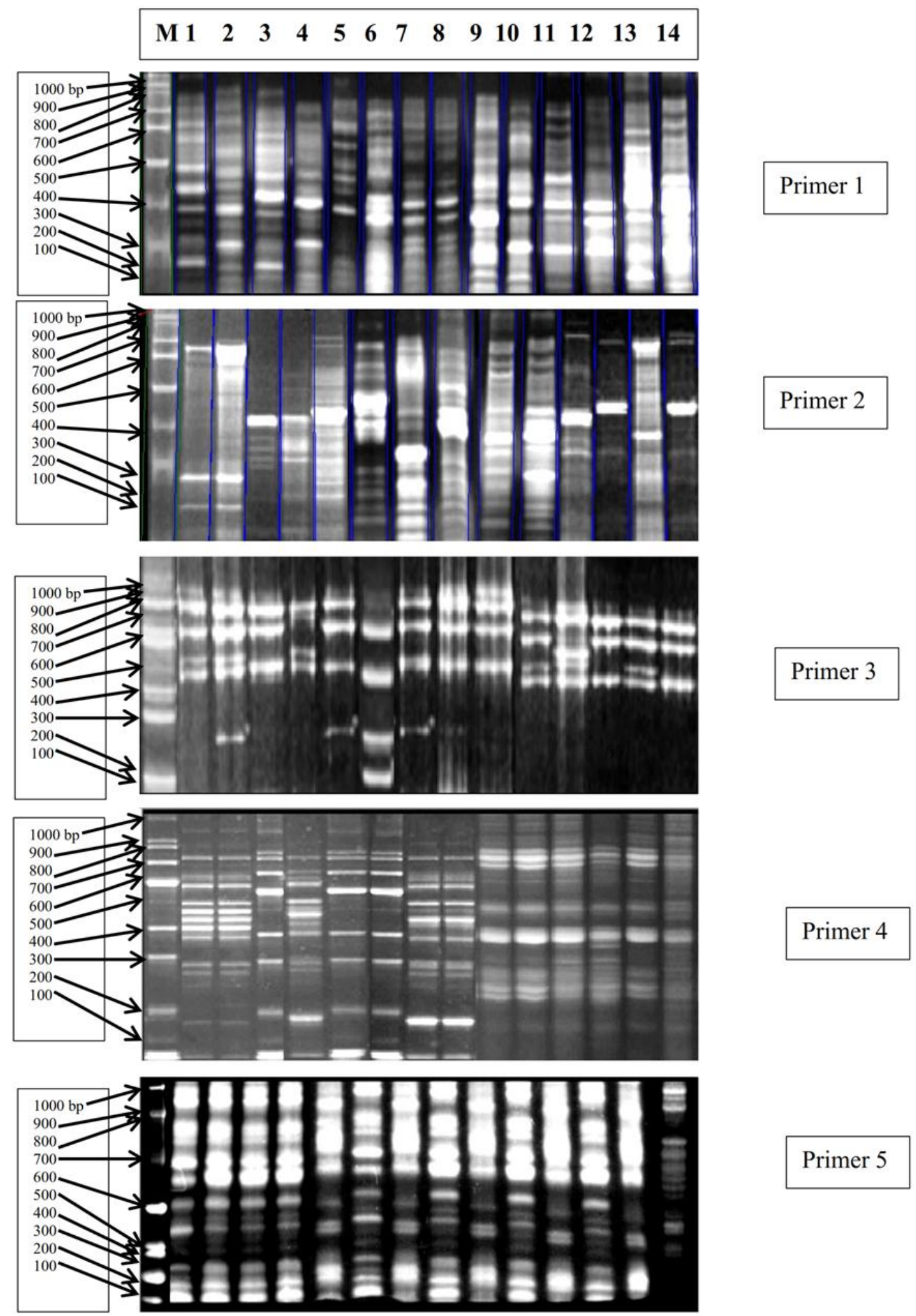

Fig. 4: RAPD pattern obtained from genomic DNA of the examined Nicotiana glauca samples growing in 14 different sites at Burg El-Arab and Amreyya districts. M, marker; numbers from 1-14 represent the study sites. 


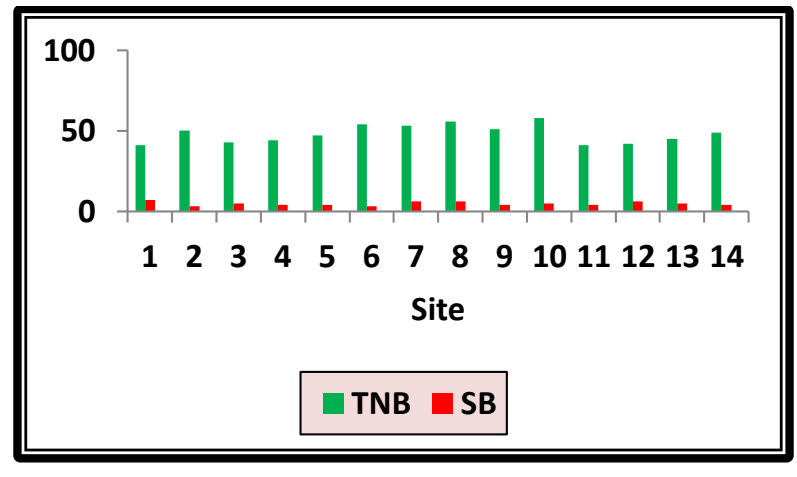

Figure 5. Variation in total number of bands, specific bands of RAPD pattern in Nicotiana glauca in 14 sites.

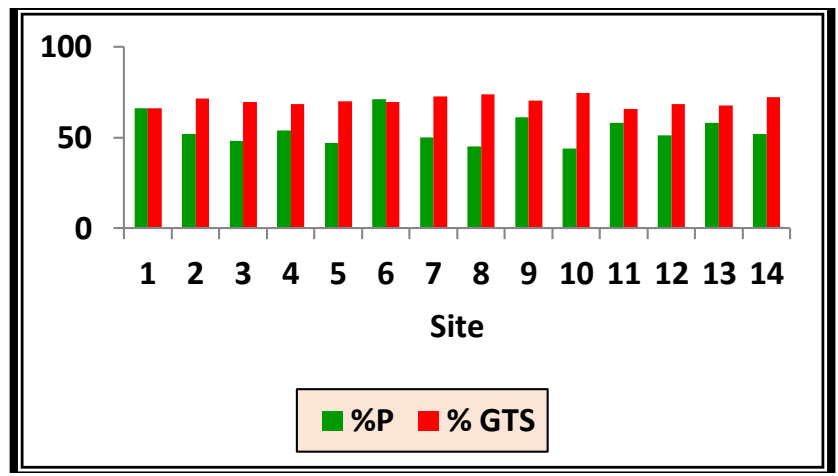

Figure 6. Variation in percentage of polymorphism (\%) and genomic template stability (GTS \%) of RAPD pattern in Nicotiana glauca in 14 sites. (a)

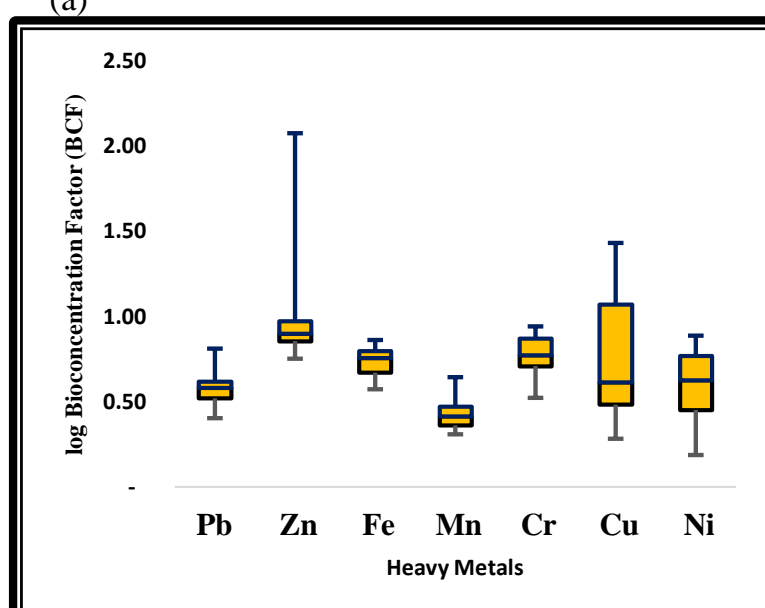

(b)

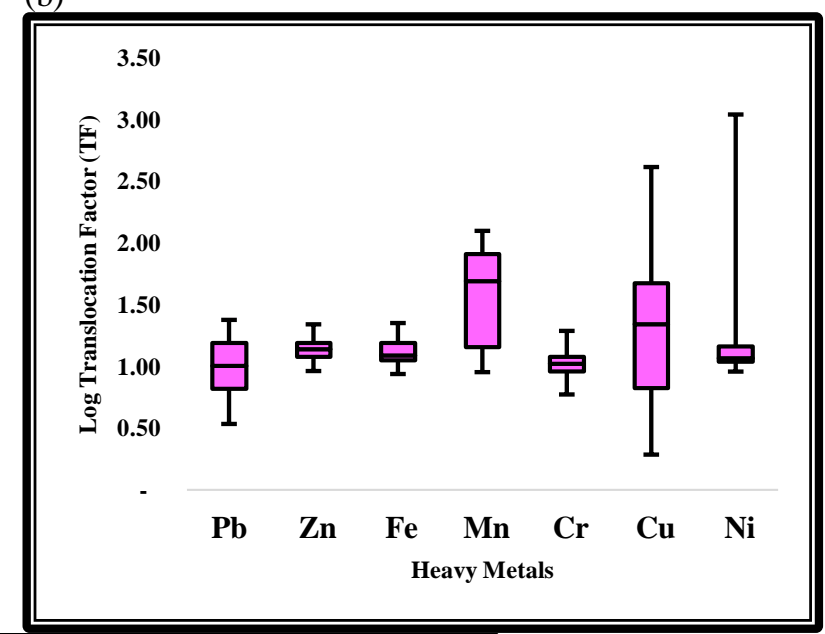

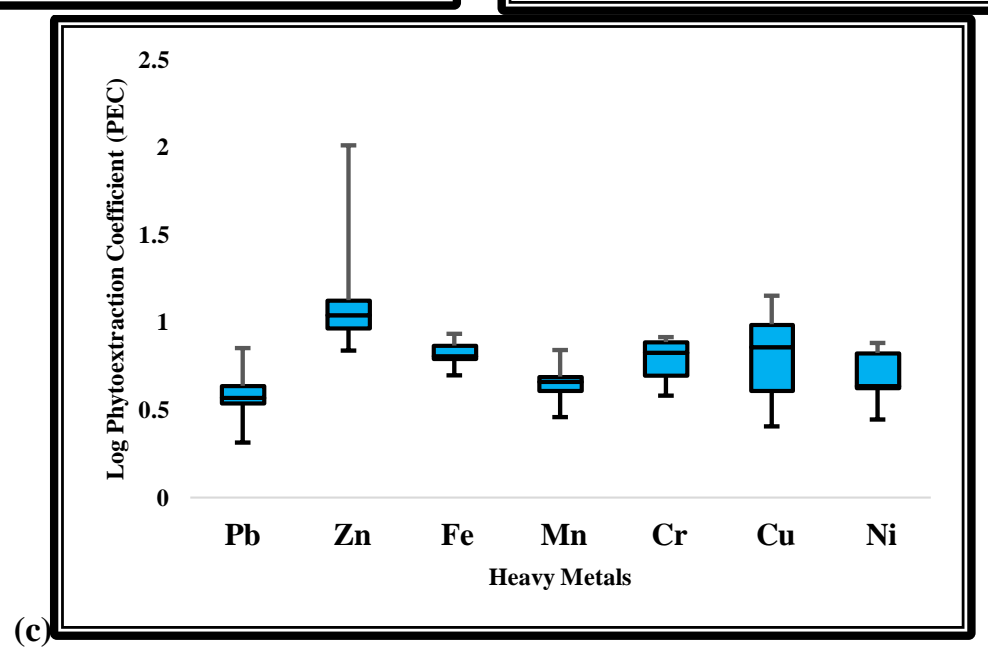

Figure 7. (a) Bioconcentration factor; BCF, (b) Translocation factor; TF and (c) Phytoextraction coefficient; PEC of heavy metals in Nicotiana glauca in 14 sites. The whiskers represent the minimum and maximum, the box represents the inter-quartile range (IQR) and the middle line represents the median. 
Table 1. Variation in phytomass of different organs, total phytomass, sharing percentage of each organ to the total phytomass as well as phytomass partitioning (root: shoot) of Nicotiana glauca growing in 14 different sites at Burg El-Arab and Amreyya districts.

\begin{tabular}{|c|c|c|c|c|c|c|c|c|c|c|}
\hline \multirow[b]{2}{*}{ Site } & \multicolumn{4}{|c|}{ 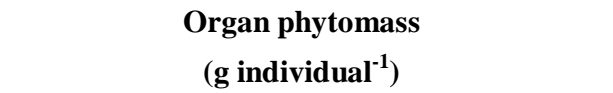 } & \multirow{2}{*}{$\begin{array}{c}\text { Total } \\
\text { phytomass } \\
\left(\text { g individual }^{-1}\right)\end{array}$} & \multicolumn{4}{|c|}{$\begin{array}{c}\text { Sharing percentage } \\
(\%)\end{array}$} & \multirow[t]{2}{*}{$\begin{array}{l}\text { Phytomass } \\
\text { Partitioning }\end{array}$} \\
\hline & Root & Stem & Leaf & Flower & & Root & Stem & Leaf & Flower & \\
\hline 1 & $116.14^{\mathrm{ef}}$ & $297.16^{\mathrm{m}}$ & $52.61^{\mathrm{i}}$ & $12.48^{\mathrm{j}}$ & $478.39^{h}$ & $24.3^{\mathrm{b}}$ & $62.1^{\mathrm{j}}$ & $10.9^{\mathrm{d}}$ & $2.6^{\mathrm{b}}$ & $0.33^{\mathrm{b}}$ \\
\hline 2 & $115.2^{\mathrm{e}}$ & $522.19^{\mathrm{i}}$ & $69.15^{\mathrm{h}}$ & $12.17^{\mathrm{j}}$ & $718.71^{f}$ & $16^{\mathrm{g}}$ & $72.6^{\mathrm{d}}$ & $9.6^{\mathrm{e}}$ & $1.6^{\mathrm{d}}$ & $0.19^{\mathrm{cd}}$ \\
\hline 3 & $138.26^{\mathrm{e}}$ & $794.96^{\mathrm{f}}$ & $43.0^{\mathrm{j}}$ & $25.78^{\mathrm{d}}$ & $1002^{\mathrm{e}}$ & $13.8^{\mathrm{j}}$ & $79.3^{\mathrm{b}}$ & $4.3^{\mathrm{j}}$ & $2.5^{\mathrm{b}}$ & $0.16^{\mathrm{de}}$ \\
\hline 4 & $95.36^{\mathrm{f}}$ & $356.23^{1}$ & $34.09^{\mathrm{k}}$ & $5.2^{\mathrm{h}}$ & $490.88^{h}$ & $19.4^{\mathrm{e}}$ & $72.6^{\mathrm{d}}$ & $6.9^{\text {gh }}$ & $1.1^{\mathrm{ef}}$ & $0.24^{\text {bcd }}$ \\
\hline 5 & $393.16^{\mathrm{a}}$ & $1833.46^{\mathrm{a}}$ & $305.27^{\mathrm{a}}$ & $22.02^{\mathrm{e}}$ & $2553.91^{\mathrm{a}}$ & $15.4^{\mathrm{h}}$ & $71.8^{\mathrm{e}}$ & $11.9^{\mathrm{c}}$ & $0.8^{\mathrm{g}}$ & $0.18^{\mathrm{cd}}$ \\
\hline 6 & $123.99^{\mathrm{e}}$ & $460.14^{\mathrm{j}}$ & $85.25^{\mathrm{e}}$ & $3.84^{\mathrm{h}}$ & $673.43^{f}$ & $18.4^{\mathrm{f}}$ & $68.3^{\mathrm{g}}$ & $12.6^{\mathrm{b}}$ & $0.5^{\mathrm{g}}$ & $0.22^{\mathrm{bcd}}$ \\
\hline 7 & $340.1^{\mathrm{b}}$ & $966.71^{\mathrm{e}}$ & $290.48^{b}$ & $44.08^{\mathrm{a}}$ & $1641.37^{\mathrm{c}}$ & $20.7^{\mathrm{d}}$ & $58.8^{\mathrm{k}}$ & $17.6^{\mathrm{a}}$ & $2.7^{\mathrm{b}}$ & $0.26^{\text {bcd }}$ \\
\hline 8 & $220.56^{\mathrm{cd}}$ & $705.89^{\mathrm{g}}$ & $69.27^{\mathrm{h}}$ & $36.1^{\mathrm{b}}$ & $1031.82^{\mathrm{e}}$ & $21.37^{\mathrm{c}}$ & $68.4^{\mathrm{g}}$ & $6.7^{\mathrm{hi}}$ & $3.4^{\mathrm{a}}$ & $0.27^{\mathrm{bc}}$ \\
\hline 9 & $243.17^{\mathrm{c}}$ & $656.4^{\mathrm{h}}$ & $78.26^{f}$ & $34.97^{\mathrm{b}}$ & $1012.8^{\mathrm{e}}$ & $24.0^{\mathrm{b}}$ & $64.8^{\mathrm{i}}$ & $7.7^{\mathrm{f}}$ & $3.4^{\mathrm{a}}$ & $0.32^{\mathrm{b}}$ \\
\hline 10 & $360.34^{\mathrm{b}}$ & $1324.24^{\mathrm{c}}$ & $206.23^{c}$ & $31.22^{\mathrm{c}}$ & $1922.03^{b}$ & $18.7^{\mathrm{f}}$ & $68.9^{f}$ & $10.7^{\mathrm{d}}$ & $1.6^{\mathrm{de}}$ & $0.23^{\mathrm{bcd}}$ \\
\hline 11 & $117.4^{\mathrm{ef}}$ & $406.44^{\mathrm{k}}$ & $70.63^{\mathrm{gh}}$ & $6.57^{\mathrm{h}}$ & $601.04^{\mathrm{g}}$ & $19.5^{\mathrm{e}}$ & $67.6^{\mathrm{h}}$ & $11.7^{\mathrm{c}}$ & $1.1^{\mathrm{f}}$ & $0.24^{\text {bcd }}$ \\
\hline 12 & $230.02^{c}$ & $291.79^{\mathrm{n}}$ & $41.36^{\mathrm{j}}$ & $16.36^{\mathrm{f}}$ & $579.53^{\mathrm{g}}$ & $39.7^{\mathrm{a}}$ & $50.3^{1}$ & $7.1^{\mathrm{g}}$ & $2.8^{\mathrm{b}}$ & $0.66^{\mathrm{a}}$ \\
\hline 13 & $196.56^{\mathrm{d}}$ & $1059.19^{\mathrm{d}}$ & $90.56^{\mathrm{d}}$ & $29.24^{\mathrm{c}}$ & $1375.56^{d}$ & $14.3^{\mathrm{i}}$ & $77.0^{\mathrm{c}}$ & $6.5^{\mathrm{i}}$ & $2.1^{\mathrm{c}}$ & $0.16^{\mathrm{de}}$ \\
\hline 14 & $71.24^{\mathrm{g}}$ & $1458.66^{\mathrm{b}}$ & $72.28^{\mathrm{j}}$ & $31.6^{\mathrm{c}}$ & $1633.78^{c}$ & $4.4^{\mathrm{k}}$ & $89.3^{\mathrm{a}}$ & $4.4^{\mathrm{j}}$ & $1.9^{\mathrm{cd}}$ & $0.05^{\mathrm{e}}$ \\
\hline $\mathbf{F}$ & $470.558 *$ & 689944.79 & $\begin{array}{c}26647.4 \\
9^{*}\end{array}$ & $\underset{*}{498.951}$ & 3965.921" & $\begin{array}{c}10066.0 \\
8^{*}\end{array}$ & $\begin{array}{l}9629 . \\
436^{*}\end{array}$ & $\begin{array}{c}1819.73 \\
7^{*}\end{array}$ & 141.920 & $30.115^{*}$ \\
\hline $\mathbf{P}$ & $<0.001^{*}$ & $<0.001^{*}$ & $<0.001^{*}$ & $<0.001^{*}$ & $<0.001^{*}$ & $<0.001^{*}$ & $\begin{array}{c}<0.00 \\
1^{*}\end{array}$ & $<0.001^{*}$ & $<0.001^{*}$ & $<0.001^{*}$ \\
\hline
\end{tabular}

F,p: $\mathrm{F}$ and $\mathrm{p}$ values for ANOVA test, significance between sites was done using Post Hoc Test (Tukey). *: Statistically significant at $\mathrm{p} \leq 0.05$. Means with common letters are not significant while means with different letters are significant. 
Table 2. Meta-analysis for the correlation between concentration of some heavy metals ( $\mathrm{Pb}, \mathrm{Zn}, \mathrm{Fe}, \mathrm{Cd}, \mathrm{Mn}, \mathrm{Cr}, \mathrm{Cu}$ and $\mathrm{Ni}$ ) in root and shoot with phytomass of root and shoot of Nicotiana glauca growing in 14 different sites at Burg El-Arab and Amreyya districts.

\begin{tabular}{|c|c|c|c|c|c|c|c|c|c|c|c|c|c|c|c|c|}
\hline \multirow[t]{2}{*}{ Sites } & \multicolumn{2}{|c|}{$\mathbf{P b}$} & \multicolumn{2}{|c|}{ Zn } & \multicolumn{2}{|c|}{$\mathrm{Fe}$} & \multicolumn{2}{|c|}{ Cd } & \multicolumn{2}{|c|}{ Mn } & \multicolumn{2}{|c|}{$\mathrm{Cr}$} & \multicolumn{2}{|c|}{$\mathrm{Cu}$} & \multicolumn{2}{|c|}{$\mathbf{N i}$} \\
\hline & $\stackrel{\overrightarrow{0}}{\simeq}$ & 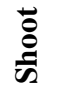 & $\overrightarrow{\stackrel{\circ}{\circ}}$ & $\frac{\overrightarrow{8}}{\mathscr{B}}$ & $\overrightarrow{\mathscr{O}}$ & ஜே: & $\overrightarrow{\stackrel{\circ}{\circ}}$ & $\frac{\overrightarrow{8}}{\tilde{b}}$ & $\overrightarrow{\mathscr{O}}$ & $\frac{\overrightarrow{8}}{\mathscr{B}}$ & $\overrightarrow{\mathscr{8}}$ & $\overrightarrow{\stackrel{B}{0}}$ & $\overrightarrow{\stackrel{\circ}{\circ}}$ & $\frac{\overrightarrow{8}}{\mathscr{a}}$ & $\overrightarrow{\ddot{\theta}}$ & $\frac{\overrightarrow{\mathscr{b}}}{\tilde{n}}$ \\
\hline 1 & $\begin{array}{c}0.8 \\
9\end{array}$ & $\begin{array}{c}0.8 \\
3\end{array}$ & $\begin{array}{l}0.8 \\
6\end{array}$ & $\begin{array}{c}0.9 \\
7\end{array}$ & $\begin{array}{l}0.9 \\
1\end{array}$ & $\begin{array}{c}0.9 \\
7\end{array}$ & $\begin{array}{c}0.9 \\
1\end{array}$ & $\begin{array}{c}0.7 \\
0\end{array}$ & $\begin{array}{c}0.9 \\
3\end{array}$ & $\begin{array}{c}0.7 \\
7\end{array}$ & $\begin{array}{c}0.9 \\
2\end{array}$ & $\begin{array}{c}0.7 \\
3\end{array}$ & $\begin{array}{c}0.6 \\
7\end{array}$ & $\begin{array}{c}0.6 \\
7\end{array}$ & $\begin{array}{c}0.7 \\
7\end{array}$ & $\begin{array}{c}0.8 \\
0\end{array}$ \\
\hline 2 & $\begin{array}{c}0.8 \\
6\end{array}$ & $\begin{array}{c}0.8 \\
7\end{array}$ & $\begin{array}{c}0.8 \\
8\end{array}$ & $\begin{array}{c}0.9 \\
5\end{array}$ & $\begin{array}{c}0.8 \\
6\end{array}$ & $\begin{array}{c}0.9 \\
4\end{array}$ & $\begin{array}{c}0.8 \\
6\end{array}$ & $\begin{array}{c}0.3 \\
2\end{array}$ & $\begin{array}{c}0.8 \\
5\end{array}$ & $\begin{array}{c}0.7 \\
1\end{array}$ & $\begin{array}{c}0.7 \\
6\end{array}$ & $\begin{array}{c}0.7 \\
6\end{array}$ & $\begin{array}{c}0.6 \\
7\end{array}$ & $\begin{array}{c}0.6 \\
8\end{array}$ & $\begin{array}{c}0.6 \\
2\end{array}$ & $\begin{array}{c}0.7 \\
7\end{array}$ \\
\hline 3 & $\begin{array}{c}0.8 \\
6\end{array}$ & $\begin{array}{c}0.8 \\
9\end{array}$ & $\begin{array}{c}0.9 \\
7\end{array}$ & $\begin{array}{c}0.9 \\
5\end{array}$ & $\begin{array}{c}0.9 \\
6\end{array}$ & $\begin{array}{c}0.9 \\
4\end{array}$ & $\begin{array}{c}0.9 \\
6\end{array}$ & $\begin{array}{c}0.7 \\
8\end{array}$ & $\begin{array}{c}0.9 \\
3\end{array}$ & $\begin{array}{c}0.7 \\
6\end{array}$ & $\begin{array}{c}0.8 \\
5\end{array}$ & $\begin{array}{c}0.6 \\
0\end{array}$ & $\begin{array}{c}0.8 \\
7\end{array}$ & $\begin{array}{c}0.6 \\
4\end{array}$ & $\begin{array}{c}0.7 \\
0\end{array}$ & $\begin{array}{c}0.7 \\
7\end{array}$ \\
\hline 4 & $\begin{array}{c}0.7 \\
2\end{array}$ & $\begin{array}{c}0.8 \\
7\end{array}$ & $\begin{array}{c}0.6 \\
2\end{array}$ & $\begin{array}{c}0.9 \\
5\end{array}$ & $\begin{array}{c}0.6 \\
6\end{array}$ & $\begin{array}{l}0.9 \\
4\end{array}$ & $\begin{array}{c}0.6 \\
6\end{array}$ & $\begin{array}{c}0.4 \\
9\end{array}$ & $\begin{array}{c}0.7 \\
9\end{array}$ & $\begin{array}{c}0.8 \\
2\end{array}$ & $\begin{array}{c}0.6 \\
4\end{array}$ & $\begin{array}{c}0.7 \\
1\end{array}$ & $\begin{array}{c}0.7 \\
5\end{array}$ & $\begin{array}{c}0.5 \\
2\end{array}$ & $\begin{array}{c}0.7 \\
5\end{array}$ & $\begin{array}{c}0.7 \\
6\end{array}$ \\
\hline 5 & $\begin{array}{c}0.8 \\
6\end{array}$ & $\begin{array}{c}0.8 \\
9\end{array}$ & $\begin{array}{c}0.9 \\
4\end{array}$ & $\begin{array}{c}0.9 \\
9\end{array}$ & $\begin{array}{c}0.9 \\
2\end{array}$ & $\begin{array}{c}0.9 \\
9\end{array}$ & $\begin{array}{c}0.9 \\
2\end{array}$ & $\begin{array}{c}0.7 \\
4\end{array}$ & $\begin{array}{c}0.9 \\
1\end{array}$ & $\begin{array}{c}0.8 \\
0\end{array}$ & $\begin{array}{c}0.8 \\
6\end{array}$ & $\begin{array}{c}0.7 \\
9\end{array}$ & $\begin{array}{c}0.7 \\
7\end{array}$ & $\begin{array}{c}0.6 \\
7\end{array}$ & $\begin{array}{c}0.7 \\
3\end{array}$ & $\begin{array}{c}0.8 \\
1\end{array}$ \\
\hline 6 & $\begin{array}{c}0.9 \\
3\end{array}$ & $\begin{array}{c}0.8 \\
9\end{array}$ & $\begin{array}{c}0.8 \\
4\end{array}$ & $\begin{array}{c}0.9 \\
9\end{array}$ & $\begin{array}{c}0.8 \\
4\end{array}$ & $\begin{array}{c}0.9 \\
9\end{array}$ & $\begin{array}{c}0.8 \\
4\end{array}$ & $\begin{array}{c}0.7 \\
0\end{array}$ & $\begin{array}{c}0.8 \\
1\end{array}$ & $\begin{array}{c}0.7 \\
0\end{array}$ & $\begin{array}{c}0.8 \\
4\end{array}$ & $\begin{array}{c}0.8 \\
1\end{array}$ & $\begin{array}{c}0.8 \\
0\end{array}$ & $\begin{array}{c}0.7 \\
0\end{array}$ & $\begin{array}{c}0.8 \\
6\end{array}$ & $\begin{array}{c}0.8 \\
2\end{array}$ \\
\hline 7 & $\begin{array}{c}0.8 \\
6\end{array}$ & $\begin{array}{c}0.8 \\
2\end{array}$ & $\begin{array}{c}0.9 \\
0\end{array}$ & $\begin{array}{c}0.9 \\
0\end{array}$ & $\begin{array}{c}0.8 \\
9\end{array}$ & $\begin{array}{c}0.8 \\
8\end{array}$ & $\begin{array}{l}0.8 \\
9\end{array}$ & $\begin{array}{c}0.7 \\
8\end{array}$ & $\begin{array}{c}0.8 \\
9\end{array}$ & $\begin{array}{c}0.2 \\
9\end{array}$ & $\begin{array}{c}0.7 \\
8\end{array}$ & $\begin{array}{c}0.7 \\
1\end{array}$ & $\begin{array}{c}0.7 \\
6\end{array}$ & $\begin{array}{c}0.6 \\
3\end{array}$ & $\begin{array}{c}0.7 \\
2\end{array}$ & $\begin{array}{c}0.7 \\
2\end{array}$ \\
\hline 8 & $\begin{array}{c}0.8 \\
1\end{array}$ & $\begin{array}{c}0.8 \\
3\end{array}$ & $\begin{array}{c}0.7 \\
9\end{array}$ & $\begin{array}{c}0.9 \\
5\end{array}$ & $\begin{array}{c}0.8 \\
3\end{array}$ & $\begin{array}{c}0.9 \\
3\end{array}$ & $\begin{array}{c}0.8 \\
3\end{array}$ & $\begin{array}{c}0.7 \\
2\end{array}$ & $\begin{array}{c}0.8 \\
6\end{array}$ & $\begin{array}{c}0.7 \\
4\end{array}$ & $\begin{array}{c}0.6 \\
7\end{array}$ & $\begin{array}{c}0.7 \\
7\end{array}$ & $\begin{array}{c}0.6 \\
9\end{array}$ & $\begin{array}{c}0.6 \\
8\end{array}$ & $\begin{array}{c}0.4 \\
9\end{array}$ & $\begin{array}{c}0.7 \\
6\end{array}$ \\
\hline 9 & $\begin{array}{c}0.8 \\
9\end{array}$ & $\begin{array}{c}0.8 \\
7\end{array}$ & $\begin{array}{c}0.9 \\
0\end{array}$ & $\begin{array}{c}0.9 \\
4\end{array}$ & $\begin{array}{c}0.9 \\
2\end{array}$ & $\begin{array}{c}0.9 \\
4\end{array}$ & $\begin{array}{c}0.9 \\
2\end{array}$ & $\begin{array}{c}0.7 \\
6\end{array}$ & $\begin{array}{c}0.8 \\
5\end{array}$ & $\begin{array}{c}0.7 \\
0\end{array}$ & $\begin{array}{c}0.7 \\
2\end{array}$ & $\begin{array}{c}0.7 \\
5\end{array}$ & $\begin{array}{c}0.8 \\
4\end{array}$ & $\begin{array}{c}0.6 \\
8\end{array}$ & $\begin{array}{c}0.5 \\
3\end{array}$ & $\begin{array}{c}0.7 \\
5\end{array}$ \\
\hline 10 & $\begin{array}{c}0.8 \\
3\end{array}$ & $\begin{array}{c}0.9 \\
5\end{array}$ & $\begin{array}{c}0.8 \\
2\end{array}$ & $\begin{array}{c}0.9 \\
7\end{array}$ & $\begin{array}{c}0.8 \\
3\end{array}$ & $\begin{array}{c}0.9 \\
9\end{array}$ & $\begin{array}{c}0.8 \\
3\end{array}$ & $\begin{array}{c}0.7 \\
0\end{array}$ & $\begin{array}{c}0.8 \\
5\end{array}$ & $\begin{array}{c}0.9 \\
0\end{array}$ & $\begin{array}{c}0.7 \\
8\end{array}$ & $\begin{array}{c}0.9 \\
0\end{array}$ & $\begin{array}{c}0.6 \\
7\end{array}$ & $\begin{array}{c}0.7 \\
9\end{array}$ & $\begin{array}{c}0.6 \\
1\end{array}$ & $\begin{array}{c}0.6 \\
9\end{array}$ \\
\hline 11 & $\begin{array}{c}0.8 \\
5\end{array}$ & $\begin{array}{c}0.8 \\
9\end{array}$ & $\begin{array}{c}0.8 \\
8\end{array}$ & $\begin{array}{c}0.9 \\
9\end{array}$ & $\begin{array}{l}0.9 \\
2\end{array}$ & $\begin{array}{c}0.9 \\
9\end{array}$ & $\begin{array}{c}0.9 \\
2\end{array}$ & $\begin{array}{c}0.7 \\
4\end{array}$ & $\begin{array}{c}0.8 \\
3\end{array}$ & $\begin{array}{c}0.8 \\
0\end{array}$ & $\begin{array}{c}0.9 \\
1\end{array}$ & $\begin{array}{c}0.6 \\
1\end{array}$ & $\begin{array}{c}0.6 \\
3\end{array}$ & $\begin{array}{c}0.7 \\
1\end{array}$ & $\begin{array}{c}0.7 \\
6\end{array}$ & $\begin{array}{c}0.8 \\
2\end{array}$ \\
\hline 12 & $\begin{array}{c}0.9 \\
1\end{array}$ & $\begin{array}{c}0.7 \\
8\end{array}$ & $\begin{array}{c}0.8 \\
6\end{array}$ & $\begin{array}{c}0.9 \\
3\end{array}$ & $\begin{array}{c}0.8 \\
8\end{array}$ & $\begin{array}{c}0.9 \\
4\end{array}$ & $\begin{array}{c}0.8 \\
8\end{array}$ & $\begin{array}{c}0.5 \\
6\end{array}$ & $\begin{array}{c}0.8 \\
6\end{array}$ & $\begin{array}{c}0.8 \\
4\end{array}$ & $\begin{array}{c}0.8 \\
3\end{array}$ & $\begin{array}{c}0.8 \\
7\end{array}$ & $\begin{array}{c}0.5 \\
6\end{array}$ & $\begin{array}{c}0.8 \\
0\end{array}$ & $\begin{array}{c}0.6 \\
1\end{array}$ & $\begin{array}{c}0.8 \\
9\end{array}$ \\
\hline 13 & $\begin{array}{c}0.9 \\
4\end{array}$ & $\begin{array}{c}0.8 \\
2\end{array}$ & $\begin{array}{c}0.9 \\
0\end{array}$ & $\begin{array}{c}0.5 \\
1\end{array}$ & $\begin{array}{c}0.8 \\
9\end{array}$ & $\begin{array}{c}0.7 \\
2\end{array}$ & $\begin{array}{c}0.8 \\
9\end{array}$ & $\begin{array}{c}0.2 \\
0\end{array}$ & $\begin{array}{c}0.8 \\
3\end{array}$ & $\begin{array}{c}0.8 \\
5\end{array}$ & $\begin{array}{c}0.7 \\
8\end{array}$ & $\begin{array}{c}0.8 \\
4\end{array}$ & $\begin{array}{c}0.8 \\
4\end{array}$ & $\begin{array}{c}0.8 \\
6\end{array}$ & $\begin{array}{c}0.6 \\
2\end{array}$ & $\begin{array}{c}0.8 \\
3\end{array}$ \\
\hline 14 & $\begin{array}{c}0.9 \\
1\end{array}$ & $\begin{array}{c}0.9 \\
1\end{array}$ & $\begin{array}{c}0.8 \\
5\end{array}$ & $\begin{array}{c}0.9 \\
4\end{array}$ & $\begin{array}{c}0.8 \\
3\end{array}$ & $\begin{array}{c}0.9 \\
4\end{array}$ & $\begin{array}{c}0.8 \\
3\end{array}$ & $\begin{array}{c}0.5 \\
8\end{array}$ & $\begin{array}{c}0.8 \\
1\end{array}$ & $\begin{array}{c}0.8 \\
4\end{array}$ & $\begin{array}{c}0.8 \\
0\end{array}$ & $\begin{array}{c}0.8 \\
7\end{array}$ & $\begin{array}{c}0.6 \\
9\end{array}$ & $\begin{array}{c}0.8 \\
0\end{array}$ & $\begin{array}{c}0.6 \\
9\end{array}$ & $\begin{array}{c}0.7 \\
3\end{array}$ \\
\hline Mean & $\begin{array}{c}0.8 \\
7\end{array}$ & $\begin{array}{c}\mathbf{0 . 8} \\
7\end{array}$ & $\begin{array}{c}0.8 \\
8\end{array}$ & $\begin{array}{c}0.9 \\
6\end{array}$ & $\begin{array}{c}0.8 \\
8\end{array}$ & $\begin{array}{c}0.9 \\
5\end{array}$ & $\begin{array}{c}0.8 \\
8\end{array}$ & $\begin{array}{c}0.6 \\
5\end{array}$ & $\begin{array}{c}0.8 \\
6\end{array}$ & $\begin{array}{c}0.7 \\
7\end{array}$ & $\begin{array}{c}0.8 \\
1\end{array}$ & $\begin{array}{c}0.7 \\
8\end{array}$ & $\begin{array}{c}0.7 \\
4\end{array}$ & $\begin{array}{c}0.7 \\
1\end{array}$ & $\begin{array}{c}0.6 \\
9\end{array}$ & $\begin{array}{c}0.7 \\
8\end{array}$ \\
\hline
\end{tabular}


Table 3. Meta-analysis for the correlation between concentration of some heavy metals ( $\mathrm{Pb}, \mathrm{Zn}, \mathrm{Fe}, \mathrm{Cd}, \mathrm{Mn}, \mathrm{Cr}, \mathrm{Cu}$ and $\mathrm{Ni}$ ) in root and shoot with percentage of polymorphism (P) and genomic template stability (GTS\%) of Nicotiana glauca growing in 14 different sites at Burg El-Arab and Amreyya districts. The differences in GTS\% values between brackets.

\begin{tabular}{|c|c|c|c|c|c|c|c|c|c|c|c|c|c|c|c|c|}
\hline \multirow[t]{2}{*}{ Sites } & \multicolumn{2}{|c|}{$\mathbf{P b}$} & \multicolumn{2}{|c|}{$\mathrm{Zn}$} & \multicolumn{2}{|c|}{$\mathbf{F e}$} & \multicolumn{2}{|c|}{ Cd } & \multicolumn{2}{|c|}{ Mn } & \multicolumn{2}{|c|}{$\mathrm{Cr}$} & \multicolumn{2}{|c|}{$\mathrm{Cu}$} & \multicolumn{2}{|c|}{$\mathbf{N i}$} \\
\hline & $\overrightarrow{\ddot{\theta}}$ & 苛 & $\overrightarrow{\mathscr{a}}$ & 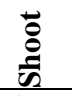 & $\stackrel{\overrightarrow{0}}{\mathscr{0}}$ & $\frac{\vec{\circ}}{\tilde{\theta}}$ & $\overrightarrow{\mathscr{O}}$ & 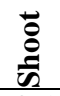 & $\stackrel{\vec{\circ}}{\mathscr{a}}$ & $\frac{\overrightarrow{8}}{\stackrel{\Xi}{\Delta}}$ & $\vec{\circ}$ & $\frac{\overrightarrow{0}}{\stackrel{0}{0}}$ & $\begin{array}{l}\overrightarrow{0} \\
\stackrel{0}{a}\end{array}$ & $\frac{\overrightarrow{8}}{\stackrel{0}{\Delta}}$ & $\stackrel{\vec{\circ}}{\mathscr{a}}$ & $\frac{\vec{\circ}}{\stackrel{0}{0}}$ \\
\hline 1 & 0.78 & 0.61 & 0.93 & 0.59 & 0.88 & 0.62 & $\begin{array}{c}0.75 \\
(0.74)\end{array}$ & $\begin{array}{c}0.5 \\
3\end{array}$ & $\begin{array}{c}0.7 \\
1\end{array}$ & $\begin{array}{c}0.8 \\
6\end{array}$ & $\begin{array}{c}0.6 \\
6\end{array}$ & $\begin{array}{c}0.7 \\
4\end{array}$ & $\begin{array}{c}0.9 \\
9\end{array}$ & $\begin{array}{c}0.8 \\
2\end{array}$ & $\begin{array}{c}0.5 \\
7\end{array}$ & $\begin{array}{c}0.8 \\
9\end{array}$ \\
\hline 2 & 0.92 & 0.67 & 0.89 & 0.61 & 0.92 & 0.62 & $\begin{array}{c}0.92 \\
(0.86)\end{array}$ & $\begin{array}{c}0.1 \\
7\end{array}$ & $\begin{array}{c}0.7 \\
2\end{array}$ & $\begin{array}{c}0.9 \\
3\end{array}$ & $\begin{array}{c}0.6 \\
0\end{array}$ & $\begin{array}{c}0.8 \\
6\end{array}$ & $\begin{array}{c}1.0 \\
0\end{array}$ & $\begin{array}{c}0.7 \\
8\end{array}$ & $\begin{array}{c}0.5 \\
7\end{array}$ & $\begin{array}{c}0.8 \\
8 \\
\end{array}$ \\
\hline 3 & 0.79 & 0.68 & 0.90 & 0.61 & 0.91 & 0.62 & $\begin{array}{c}0.05 \\
(0.99)\end{array}$ & $\begin{array}{c}0.4 \\
2\end{array}$ & $\begin{array}{c}0.7 \\
9\end{array}$ & $\begin{array}{c}0.8 \\
6\end{array}$ & $\begin{array}{c}0.6 \\
6\end{array}$ & $\begin{array}{c}0.9 \\
9\end{array}$ & $\begin{array}{c}1.0 \\
0\end{array}$ & $\begin{array}{c}0.8 \\
6\end{array}$ & $\begin{array}{c}0.5 \\
6\end{array}$ & $\begin{array}{c}0.8 \\
8\end{array}$ \\
\hline 4 & 0.93 & 0.67 & 0.90 & 0.60 & 0.92 & 0.62 & $\begin{array}{c}0.91 \\
(0.93) \\
\end{array}$ & $\begin{array}{c}0.7 \\
8\end{array}$ & $\begin{array}{c}0.9 \\
8 \\
\end{array}$ & $\begin{array}{c}0.5 \\
2 \\
\end{array}$ & $\begin{array}{c}0.6 \\
6 \\
\end{array}$ & $\begin{array}{c}0.9 \\
3 \\
\end{array}$ & $\begin{array}{c}1.0 \\
0\end{array}$ & $\begin{array}{c}0.8 \\
1 \\
\end{array}$ & $\begin{array}{c}0.5 \\
6 \\
\end{array}$ & $\begin{array}{c}0.9 \\
0\end{array}$ \\
\hline 5 & 0.84 & 0.64 & 0.90 & 0.60 & 0.88 & 0.62 & $\begin{array}{c}0.91 \\
(0.90) \\
\end{array}$ & $\begin{array}{c}0.4 \\
0\end{array}$ & $\begin{array}{c}0.8 \\
6 \\
\end{array}$ & $\begin{array}{c}0.8 \\
4 \\
\end{array}$ & $\begin{array}{c}0.6 \\
7 \\
\end{array}$ & $\begin{array}{c}0.9 \\
0\end{array}$ & $\begin{array}{c}1.0 \\
0\end{array}$ & $\begin{array}{c}0.8 \\
7 \\
\end{array}$ & $\begin{array}{l}0.5 \\
6 \\
\end{array}$ & $\begin{array}{c}0.8 \\
8 \\
\end{array}$ \\
\hline 6 & 0.91 & 0.63 & 0.88 & 0.60 & 0.86 & 0.62 & $\begin{array}{c}0.91 \\
(0.85)\end{array}$ & $\begin{array}{c}0.5 \\
6\end{array}$ & $\begin{array}{c}0.8 \\
6\end{array}$ & $\begin{array}{c}0.9 \\
6\end{array}$ & $\begin{array}{c}0.6 \\
6\end{array}$ & $\begin{array}{c}0.8 \\
5\end{array}$ & $\begin{array}{c}0.9 \\
9\end{array}$ & $\begin{array}{c}0.8 \\
3\end{array}$ & $\begin{array}{c}0.5 \\
7\end{array}$ & $\begin{array}{c}0.8 \\
8\end{array}$ \\
\hline 7 & 0.97 & 0.62 & 0.86 & 0.60 & 0.87 & 0.62 & $\begin{array}{c}0.86 \\
(0.88) \\
\end{array}$ & $\begin{array}{c}0.4 \\
2 \\
\end{array}$ & $\begin{array}{c}0.7 \\
9 \\
\end{array}$ & $\begin{array}{c}0.9 \\
6 \\
\end{array}$ & $\begin{array}{c}0.6 \\
2 \\
\end{array}$ & $\begin{array}{c}0.8 \\
8 \\
\end{array}$ & $\begin{array}{c}1.0 \\
0\end{array}$ & $\begin{array}{c}0.8 \\
1 \\
\end{array}$ & $\begin{array}{c}0.5 \\
1 \\
\end{array}$ & $\begin{array}{c}0.8 \\
9 \\
\end{array}$ \\
\hline 8 & 0.86 & 0.65 & 0.89 & 0.61 & 0.87 & 0.61 & $\begin{array}{c}0.76 \\
(0.81) \\
\end{array}$ & $\begin{array}{c}0.4 \\
0\end{array}$ & $\begin{array}{c}0.9 \\
4 \\
\end{array}$ & $\begin{array}{c}0.9 \\
0\end{array}$ & $\begin{array}{c}0.6 \\
5\end{array}$ & $\begin{array}{c}0.8 \\
1\end{array}$ & $\begin{array}{c}1.0 \\
0\end{array}$ & $\begin{array}{c}0.7 \\
7\end{array}$ & $\begin{array}{c}0.5 \\
6 \\
\end{array}$ & $\begin{array}{c}0.9 \\
0\end{array}$ \\
\hline 9 & 0.89 & 0.67 & 0.87 & 0.59 & 0.86 & 0.63 & $\begin{array}{c}0.86 \\
(0.89) \\
\end{array}$ & $\begin{array}{c}0.3 \\
7 \\
\end{array}$ & $\begin{array}{c}0.8 \\
2\end{array}$ & $\begin{array}{c}0.9 \\
4\end{array}$ & $\begin{array}{c}0.6 \\
6 \\
\end{array}$ & $\begin{array}{c}0.8 \\
9\end{array}$ & $\begin{array}{c}1.0 \\
0\end{array}$ & $\begin{array}{c}0.7 \\
9\end{array}$ & $\begin{array}{c}0.5 \\
7\end{array}$ & $\begin{array}{c}0.9 \\
1\end{array}$ \\
\hline 10 & 0.89 & 0.67 & 0.89 & 0.59 & 0.87 & 0.63 & $\begin{array}{c}0.76 \\
(0.87) \\
\end{array}$ & $\begin{array}{c}0.4 \\
2 \\
\end{array}$ & $\begin{array}{c}0.8 \\
8 \\
\end{array}$ & $\begin{array}{c}0.8 \\
9 \\
\end{array}$ & $\begin{array}{c}0.6 \\
7 \\
\end{array}$ & $\begin{array}{c}0.8 \\
7 \\
\end{array}$ & $\begin{array}{c}1.0 \\
0\end{array}$ & $\begin{array}{c}0.7 \\
7 \\
\end{array}$ & $\begin{array}{c}0.5 \\
7 \\
\end{array}$ & $\begin{array}{c}1.0 \\
0\end{array}$ \\
\hline 11 & 0.91 & 0.63 & 0.89 & 0.59 & 0.80 & 0.62 & $\begin{array}{c}0.89 \\
(0.88) \\
\end{array}$ & $\begin{array}{c}0.4 \\
0 \\
\end{array}$ & $\begin{array}{c}0.9 \\
1 \\
\end{array}$ & $\begin{array}{c}0.8 \\
7 \\
\end{array}$ & $\begin{array}{c}0.6 \\
6 \\
\end{array}$ & $\begin{array}{c}0.8 \\
8 \\
\end{array}$ & $\begin{array}{c}1.0 \\
0 \\
\end{array}$ & $\begin{array}{c}0.7 \\
9 \\
\end{array}$ & $\begin{array}{c}0.5 \\
7 \\
\end{array}$ & $\begin{array}{c}0.8 \\
1 \\
\end{array}$ \\
\hline 12 & 0.85 & 0.61 & 0.89 & 0.61 & 0.86 & 0.62 & $\begin{array}{c}0.87 \\
(0.82)\end{array}$ & $\begin{array}{c}0.7 \\
6 \\
\end{array}$ & $\begin{array}{c}0.8 \\
6 \\
\end{array}$ & $\begin{array}{c}0.7 \\
3 \\
\end{array}$ & $\begin{array}{c}0.6 \\
6 \\
\end{array}$ & $\begin{array}{c}0.8 \\
2 \\
\end{array}$ & $\begin{array}{c}1.0 \\
0\end{array}$ & $\begin{array}{c}0.8 \\
1 \\
\end{array}$ & $\begin{array}{c}0.5 \\
6\end{array}$ & $\begin{array}{c}0.8 \\
7 \\
\end{array}$ \\
\hline 13 & 0.91 & 0.65 & 0.87 & 0.51 & 0.86 & 0.62 & $\begin{array}{c}0.89 \\
(0.88) \\
\end{array}$ & $\begin{array}{c}0.7 \\
8 \\
\end{array}$ & $\begin{array}{c}0.7 \\
6 \\
\end{array}$ & $\begin{array}{c}0.8 \\
6 \\
\end{array}$ & $\begin{array}{c}0.6 \\
6 \\
\end{array}$ & $\begin{array}{c}0.8 \\
8 \\
\end{array}$ & $\begin{array}{c}1.0 \\
0 \\
\end{array}$ & $\begin{array}{c}0.7 \\
8 \\
\end{array}$ & $\begin{array}{c}0.5 \\
7 \\
\end{array}$ & $\begin{array}{c}0.8 \\
9 \\
\end{array}$ \\
\hline 14 & 0.73 & 0.64 & 0.90 & 0.61 & 0.91 & 0.62 & $\begin{array}{c}0.93 \\
(0.80)\end{array}$ & $\begin{array}{c}0.7 \\
1 \\
\end{array}$ & $\begin{array}{c}0.8 \\
5\end{array}$ & $\begin{array}{c}0.9 \\
3 \\
\end{array}$ & $\begin{array}{c}0.6 \\
3 \\
\end{array}$ & $\begin{array}{c}0.8 \\
0 \\
\end{array}$ & $\begin{array}{c}1.0 \\
0\end{array}$ & $\begin{array}{c}0.7 \\
5\end{array}$ & $\begin{array}{c}0.5 \\
6\end{array}$ & $\begin{array}{c}1.0 \\
0\end{array}$ \\
\hline
\end{tabular}

$1.3 \mathrm{He}$
avy metal
equations

Regarding BCF, all heavy metals

exhibited high values in all sites except $\mathrm{Cd}$ which

exhibited its high value only in site 14. Respecting PEC, the maximum values were attained in sites 11 (for $\mathrm{Pb}$ and $\mathrm{Cd}$ ), 12 (for $\mathrm{Fe}$ and $\mathrm{Mn}$ ) and $14(\mathrm{Zn}$, $\mathrm{Ni}$ and $\mathrm{Cr}$ ).

However, the minimum values of $\mathrm{Fe}, \mathrm{Mn}$ and $\mathrm{Cr}$ were achieved in site 7. Finally, all the metals attained considerably high values in all sites respecting TF compared to BCF and PEC (Figure 3).

\subsection{Random amplified polymorphic DNA (RAPD)}

For RAPD, one-hundred fifty nine out of 363 bands were polymorphic with $43.8 \%$ (Figure 4 ). The total number of bands ranged from 41 (sites 1 and 11) to 58 bands (site 10) whereas, the number of specific bands varied from 3 (sites 2 and site 6) to 7 bands (site1) (Figure 5). Number of new appeared and disappeared bands were expressed through the GTS\%, which fluctuated 65.8 \% (site 11) to $74.6 \%$ (site 10) (Figure 6).

\subsection{Box and Whiskers plot}

The data set of BCF, TF and PEC from Box and Whiskers plot were illustrated in Figure $7 \mathrm{a}, \mathrm{b}$ and $\mathrm{c}$ respectively. In BCF and $\mathrm{PEC}, \mathrm{Cu}$ attained larger interquartile range (IQR) however, in TF $\mathrm{Zn}$ achieved the larger one. The highest value of median and positive skewed (upward) was in BCF and PEC while Mn and Ni remained in TF.

\subsection{Meta-analysis of heavy metals and RAPD}

The Meta-analysis appeared that the concentration of heavy metals was correlated with phytomass in root and shoot of the plant species in the 14 sites. It was proved that the correlation diverse between metals among the different sites (Table 2). In root, it was recorded that $\mathrm{Pb}, \mathrm{Mn}$ and $\mathrm{Cr}$ attained small range between minimum and maximum values; so, the concentration of these metals showed high significant correlation with phytomass in all the study sites. It was noticeable that all metals showed $100 \%$ significant correlation in all sites except $\mathrm{Ni}$ which attained $7.1 \%$ non-significance. In shoot, it was obtained that $\mathrm{Pb}, \mathrm{Fe}$ and $\mathrm{Ni}$ attained high significant correlation with phytomass in all the study sites. It was obvious that all metals showed $100 \%$ significant correlation in all sites except $\mathrm{Cd}$ and $\mathrm{Mn}$ which attained $21.4 \%$ and $7.1 \%$ non-significance, respectively. 
From the Meta-analysis, the correlation coefficients between the polymorphism percentages or GTS\% and some metals in root, such as $\mathrm{Cu}, \mathrm{Ni}, \mathrm{Zn}$ and $\mathrm{Cr}$, showed small range between minimum and maximum values and in shoot $\mathrm{Pb}$, $\mathrm{Zn}$ and $\mathrm{Fe}$, so the concentration of these metals showed high significant correlation in all sites. All metals achieved 100\% significant correlation in all sites except $\mathrm{Cd}$ which attained $7.1 \%$ non-significance. In shoot, the highest significant correlation with percentage of polymorphism or GTS\% were in $\mathrm{Mn}, \mathrm{Cr}, \mathrm{Cu}$ and $\mathrm{Ni}$, while the lowest significant correlation was in $\mathrm{Cd}$. In roots, $\mathrm{Cu}$ attained the highest correlation where a the lowest achieved for Ni (Table 3).

\section{DISCUSSION}

The most popular uses of ecological Meta-analysis were to explore the importance of plant growth and allocation plasticity in species adaptation to the environment [3, 22, 23, 24, 25]. Nicotiana glauca was a pioneer plant in many disturbed ecosystems and has potential for use in bioremediation of heavy metal-contaminated sites [26, 27]. Variability of phytomass could be explained by several biotic and abiotic factors such as environmental pollution, distribution of plant species and ecosystem disturbances [28, 29]. The average phytomass of stem attained the highest values in all sites and therefore achieved high sharing percentages relative to root. Solanaceae significantly shifted from a high allocation to roots at low soil-HM levels, then to shoots at intermediate levels, and finally to roots at high levels. In the context of phytoremediation, plants expressing a high level of allocation plasticity shifted their biomass allocation from shoots to roots to circumvent the challenges of increasing soil-HM conditions, notably HM toxicity and edaphic changes resulting in soil-nutrient imbalances [30]. Both BCF and TF values more than one, indicated that some species were potentially useful for remedying HM-contaminated soil and introduce as HMhyperaccumulator plant [31]. It was recorded that all metals showed 100\% significant correlation in all sites except Ni in root and $\mathrm{Cd}$ in shoot. The roots accumulated significantly higher concentrations of $\mathrm{Cd}$ and $\mathrm{Zn}$ followed by stems then leaves [32, 33]. Meta-analysis study on the capacity of plants to absorb $\mathrm{Cu}, \mathrm{Zn}$, and $\mathrm{Cd}$ was indicated that uptake of one from these metals was generally highly correlated with the uptake of the others [34]. Box and whisker plot (boxplots) was a graph that presented information from a five-number summary (minimum, quartile 1, median, quartile 2 and maximum). It was especially useful for indicating whether a distribution was skewed and whether there were potential unusual observations (outliers) in the data set [35]. Boxplots were considered a way of summarizing a set of data on an interval scale and showed the shape of the distribution, its central value and its variability [36]. It was apparent that the data set of $\mathrm{Cu}$ attained a larger interquartile range (IQR) with respect to $\mathrm{BCF}, \mathrm{TF}$ and PEC. The cupper principally acted as a cofactor for several enzymes and played important roles in plant growth and development [37]. The RAPD technique can be used for genotoxicity assessment and mutations in the cells [38]. The RAPD method offered an applicable assay in determining the effects of heavy metals on DNA profiles [39, 40, 41, 42, 43]. The site 10 was discriminated with the highest total number of bands and genomic template stability (GTS \%), and the lowest percentage of polymorphism. However, the site 1 recorded the highest values of percentage of polymorphism and specific bands. The previous results signified that site 10 was highly adapted to the pollution with heavy metals contrary to site 1 . Meanwhile, the study detected the relatively high GTS\% (65.8- 74.6) in all sites which reflected the great ability of $N$. glauca to accumulate heavy metals without severe changes in its DNA with high tolerance limits. The results were in consistent with Payus [44] who reported that heavy metals had no mutation effect on DNA of Nepenthes plant which can be considered as hyperaccumulator species. The percentage of polymorphism and GTS\% were correlated with heavy metal concentrations in root and shoot; except Cd. The current study accepted the validity of Meta-analysis and confirmed the hypothesis that $N$. glauca was considered a greatly hyperaccumulator species and consequently its use as phytoremediator species.

\section{CONCLUSION}

Pollution by heavy metals is an urgent problem in Egypt and some plants are well adaptive and exhibits alternative mechanisms in dealing with harsh environments. Meta-analysis revealed that $N$. glauca was a great hyperaccumulator species that can accumulate high levels of different heavy metals and adapted to the polluted environments without severe changes in its genetic material that was appeared through high percentage of GTS.

\section{CONFLICT OF INTERESTS}

There are no conflicts of interests.

\section{REFERENCES}

[1] Thorsteinson, T.J., 2003. Job attitudes of part-time vs. full-time workers. Journal of Occupational and Organizational Psychology. 76: 151-177. DOI: 10.1348/096317903765913687.

[2] Dong, C., Y, Ma., D, Zheng., M. Wisneiwski and Z-M. Cheng., 2018. Meta-analysis of the effect of overexpression of dehydration-responsive element binding family genes on temperature stress tolerance and related responses. Front Plant Sci. 9: 713. DOI: 10.3389/fpls.2018.00713.

[3] Lortie, C.J., G, Stewart., H. Rothstein and J. Lau., 2014. How to critically read ecological meta-analyses. Research Synthesis Methods. 94: 7-16. DOI: 10.1002/jrsm.1109.

[4] Schreck, E., Y, Foucault., F, Geret., P. Pradere and C. Dumat., 2011. Influence of soil ageing on bioavailability and ecotoxicity of lead carried by process waste metallic ultrafine particles. Chemosphere. 85: 1555-1562. DOI: 10.1016/j.chemosphere.2011.07.059. 
[5] Thorsteinson, T.J., 2003. Job attitudes of part-time vs. full-time workers. Journal of Occupational and Organizational Psychology. 76: 151-177. DOI: 10.1348/096317903765913687.

[6] Dong, C., Y, Ma., D, Zheng., M. Wisneiwski and Z-M. Cheng., 2018. Meta-analysis of the effect of overexpression of dehydration-responsive element binding family genes on temperature stress tolerance and related responses. Front Plant Sci. 9: 713. DOI: 10.3389/fpls.2018.00713.

[7] Lortie, C.J., G, Stewart., H. Rothstein and J. Lau., 2014. How to critically read ecological meta-analyses. Research Synthesis Methods. 94: 7-16. DOI: 10.1002/jrsm.1109.

[8] Schreck, E., Y, Foucault., F, Geret., P. Pradere and C. Dumat., 2011. Influence of soil ageing on bioavailability and ecotoxicity of lead carried by process waste metallic ultrafine particles. Chemosphere. 85: 1555-1562. DOI: 10.1016/j.chemosphere.2011.07.059.

[9] Anjum, N.A., I, Ahmad., I, Mohmood., M, Pacheco., A.C, Duarte., E, Pereira., S, Umar., A, Ahmad., N.A, Khan., M. Iqbal and M.N.V. Prasad., 2012. Modulation of glutathione and its related enzymes in plants' responses to toxic metals and metalloids-a review. Environmental and Experimental Botany. 75: 307-324. DOI: 10.1016/j.envexpbot.2011.07.002.

[10] Gjorgieva, D., T. Kadifkova-Panovska and S. Mitrev., 2012. Assessment of the genotoxicity of heavy metals in Phaseolus vulgaris L. as a model plant system by random amplified polymorphic DNA (RAPD) analysis. Journal of Environmental Science and Health. 47(3): 366-373. DOI: 10.1080/10934529.2012.645784.

[11] Valladares, F., E. Gianoli and J.M. Gomez., 2007. Ecological limits to plant phenotypic plasticity. New Phytologist. $176: 749$ -763. DOI: $10.1111 / \mathrm{j} .1469-8137.2007 .02275 . x$.

[12] Varone, L and L, Gratani., 2007. Physiological response of eight mediterranean maquis species to low air temperatures during winter. Photosynthetica. 45: 385-391. DOI: 10.1007/s11099-007-0065-6.

[13] El-Darier, S.M and H.A, Ahmed., 2015. Enhancement of drought tolerance of Vicia faba L. via low strength aqueous extract of Nicotiana glauca L. in Egypt. Indian Journal of Plant Sciences. 4: 88-95. Available from: http://www.cibtech.org/J-PlantSciences/PUBLICATIONS/2015/Vol-4-No-3/13-JPS-018-SALAMA-ENHANCEMENT.

[14] El-Kenany, E.T., S.M, El-Darier., A.A. Abdellatif and S.M. Shaklol., 2017. Allelopathic potential of invasive species; Nicotiana glauca Graham on Some ecological and physiological aspects of Medicago sativa L. and Triticum aestivum L. Rendiconti Lincei Journal. 28: 159-167. DOI: 10.1007/s12210-016-0587-6.

[15] Audet, $\mathrm{P}$ and C, Charest., 2008. Allocation plasticity and plant-metal partitioning: next term meta-analytical perspectives in phytoremediation. Environmental Pollution. 156(2): 290-296. DOI: 10.1016/j.envpol.2008.02.010.

[16] AOAC (Association of Official Analytical Chemists), 1995. Official Methods of Analysis, 16 ${ }^{\text {th }}$ Edition, Washington, DC. ISBN: 0-935584-24-0.

[17] Wai, H.O., A.N. Lai and L.E. Don., 2008. Assessment of Pb uptake, translocation and immobilization in kenaf (Hibiscus cannabinus L.) for phytoremediation of sand tailings. Journal of Environmental Sciences. 20: 1341-1347. DOI: 10.1016/S1001-0742(08)62231-7.

[18] Rotkittikhun, P., M, Kruatrachue., R, Chaiyarat., C, Ngernsaengsaruay., P, Pokethitiyook., A. Paijitprapaporn and A.J. Baker., 2006. Uptake and accumulation of lead by plants from the Bo Ngam lead mine area in Thailand. Environmental Pollution. 144: 681-8. DOI: 10.1016/j.envpol.2005.12.039.

[19] Lopera-Barrero, N.M., R.P, Ribeiro., R.N, Sirol., J.A, Povh., P.C, Gomes., D.J.R. Streit and L. Vargas., 2008. Genetic characterization of Brycon orbignyanus stocks used in restocking programs. Revista MVZ Córdoba. 13: 1110-1119. http://www.scielo.org.co/scielo.php?script=sci_arttext\&pid=S0122-02682008000100002.

[20] Cimino, M.C., 2006. Comparative overview of current international strategies and guidelines for genetic toxicology testing for regulatory purposes. Environmental and Molecular Mutagenesis. 47: 362-390. DOI: 10.1002/em.20216.

[21] Zar, J.H., 1999. Biostatistical Analysis, $4^{\text {th }}$ Edition. Prentice-Hall, Upper-Saddle River, NJ. ISBN: $978-0130815422$.

[22] Agoramoorthy, G., F. Chen and M.J. Hsu., 2008. Threat of heavy metal pollution in halophytic and mangrove plants of Tamil Nadu, India. Environmental Pollution. 155: 320-326. DOI: 10.1016/j.envpol.2007.11.011.

[23] Borenstein, M., L.V, Hedges., J.P.T. Higgins and H.R. Rothstein., 2005. Comprehensive Meta-analysis (Version 2.2.027).

[24] Hedges, L.V and I, Olkin., 1985. Statistical Methods for Meta-analysis. Academic Press, Orlando, 284 FL, Pp. 369. ISBN: 9780123363800.

[25] Lipsey, M.W and D.B, Wilson., 2001. Practical Meta-analysis. SAGE Publications, Thousand Oaks, Pp. 291.ISBN: 9780761921684.

[26] Koricheva, J and J, Gurevitch., 2013. Place of meta-analysis among other methods of research synthesis. Handbook of Metaanalysis in Ecology and Evolution. Princeton University Press, Princeton and Oxford, Pp.520. ISBN: 9780691137292.

[27] Taub, D.R., 2007. A Meta-analysis of studies on plant growth rate and allocation to roots and shoots. Nature Proceedings. 1733. DOI: $10.1038 /$ npre.2007.185.1

[28] He, Q., M.D. Bertness and A.H. Altieri., 2013. Global shifts towards positive species interactions with increasing environmental stress. Ecology Letters. 16: 695-706. DOI: 10.1111/ele.12080

[29] Liczner, A.R and C.J, Lortie., 2014. A global Meta-analytic contrast of cushion-plant effects on plants and on arthropods. PeerJ. 2: 265. DOI: 10.7717/peerj.265

[30] Barazani, O., S, Peramachi., U, Manandhar., R. Vulkan and A. Golan-Goldhirsh., 2004. Heavy metal accumulation by Nicotiana glauca Graham in a solid waste disposal site. Chemosphere. 54: 867-872. DOI: 10.1016/j.chemosphere.2003.10.005. 
[31] González, A., W, Tezara., E. Rengifo and A. Herrera., 2012. Ecophysiological responses to drought and salinity in the composition invader Nicotiana glauca. Brazilian journal of Plant Physiology. 24 (3): 213-22. DOI: 10.1590/S167704202012000300008.

[32] Sicard, C., L, Saint-Andre., D. Gelhaye and J. Ranger., 2006. Effect of initial fertilization on biomass and nutrient content of Norway spruce and douglas-fir plantations at the same site. Trees. 20: 229-246. DOI: 10.1007/s00468-005-0030-6.

[33] Paoli, G.D., M.C. Lisa and J.W.F. Slik., 2008. Soil nutrients affect spatial patterns of aboveground biomass and emergent tree density in southwestern Borneo. Oecologia. 155(2): 287-299. DOI: 10.1007/s00442-007-0906-9.

[34] Farrar, J.F and D.L, Jones., 2000. The control of carbon acquisition by roots. New Phytologist. 147: 43-53. DOI: 10.1046/j.1469-8137.2000.00688.x.

[35] Rezvani, M and F, Zaefarian., 2011. Bioaccumulation and translocation factors of cadmium and lead in Aeluropus littoralis. Australian Journal of Agricultrual Engineering. 2(4): 114-119. DOI: 10.15171/EHEM.2017.xx.

[36] Liu, H., H, Wang., Y, Zhang., W. Jiashuo and Y. Jikun., 2019. Comparison of heavy metal accumulation and cadmium phytoextraction rates among ten leading tobacco (Nicotiana tabacum L.) cultivars in China. International Journal of Phytoremediation. DOI: 10.1080/15226514.2018.1556589.

[37] Sun, H., Z, Wang., P. Gao and P. Liu., 2013. Selection of aquatic plants for phytoremediation of heavy metal in electroplate wastewater. Acta Physiologiae Plantarum. 35: 355-364. DOI: 10.1007/s11738-012-1078-8.

[38] Li, J., H. Yu and Y. Luan., 2015. Meta-analysis of the copper, zinc, and cadmium absorption capacities of aquatic plants in heavy metal-polluted water. International Journal of Environmental Research and Public Health. 12: 14958-14973. DOI: 10.3390/ijerph121214959.

[39] Rousseeuw, P.J., I. Ruts and J.W. Tukey., 1999. The bagplot: a bivariate boxplot. The American Statistician. 53 (4): $382-387$. DOI: $10.1080 / 00031305.1999 .10474494$.

[40] Hubert, M and E, Vandervieren., 2008. An adjusted boxplot for skewed distribution. Computational Statistics and Data Analysis. 52(12): 5186-5201. DOI: 10.1016/j.csda.2007.11.008.

[41] Mateos-Naranjo, E., A, Gallé., I, Florez-Sarasa., J.A, Perdomo., J, Galmés., M. Ribas-Carbó and J. Flexas., 2015. Assessment of the role of silicon in the $\mathrm{Cu}$-tolerance of the $\mathrm{C}_{4}$ grass Spartina densiflora. Journal of Plant Physiology. 178: 74-83. DOI: 10.1016/j.jplph.2015.03.001.

[42] Atienzar, F.A., B, Cordi., M.B, Donkin., A.J, Evenden., A.N. Jha and M.H. Depledge., 2000. Comparison of ultravioletinduced genotoxicity detected by random amplified polymorphic DNA with chlorophyll fluorescence and growth in a marine macroalgae, Palmaria palmate. Aquatic Toxicolology. 50: 1-12. DOI: 10.1016/S0166-445X(99)00100-9.

[43] Bardakci, F., 2001. Random amplified polymorphic DNA (RAPD) markers. Turkish Journal of Biology. 25: 185-196. Available from: http://journals.tubitak.gov.tr/biology/issues/biy-01-25-2/biy-25-2-10-9909-12.pdf.

[44] Atienzar, F.A., P, Venier., J.H.A. Awadhesh and M.H. Depledge., 2002. Evaluation of the random amplified polymorphic DNA (RAPD) assay for the detection of DNA damage and mutations. Toxicology and Environmental Mutagenesis. 521: 151163. https://www.ncbi.nlm.nih.gov/pubmed/12438012.

[45] Enan, M.R., 2006. Application of random amplified polymorphic DNA (RAPD) to detect the genotoxic effect of heavy metals. Biotechnology and Application Biochemistry. 43: 147-154. DOI: 10.1042/BA20050172.

[46] Al-Qurainy, F., A.A. Alameri and S. Khan., 2010. RAPD profile for the assessment of genotoxicity on a medicinal plant Eruca sativa. Journal of Medicinal Plants Research. 4(7): 579-586. DOI: 10.5897/JMPR10.062.

[47] Gjorgieva, D., T, Kadifkova-Panovska., T, Ruskovska., K. Bačeva and T. Stafilov., 2013. Influence of heavy metal stress on antioxidant status and DNA damage in Urtica dioica. BioMed Research International. Pages 6. DOI: 10.1155/2013/276417.

[48] Payus, C., T.S. Ying and W.N. Kui., 2016. Effect of heavy metal contamination on the DNA mutation of Nepenthes plant from abandoned mine. Research Journal of Environmental Toxicology. 10: 193-204. DOI: 10.3923/rjet.2016.193.204 